\title{
Palma epistológrafo
}

Pedro Díaz Ortiz Instituto Ricardo Palma/Universidad Ricardo Palma tarmapap@yahoo.es Lima-Perú

\section{Resumen}

Entre los más diversos géneros literarios cultivados por Ricardo Palma, los menos conocidos son el periodístico, el epistolar y la traducción literaria. En Palma epistológrafo tratamos, en líneas generales, sobre las cartas enviadas por Ricardo Palma a escritores peruanos, hispanoamericanos y españoles, $\mathrm{y}$, asimismo, sobre las cartas de escritores peruanos, hispanoamericanos y españoles enviadas a Ricardo Palma.

Palabras claves: Ricardo Palma, cartas, tradición, crónicas.

\begin{abstract}
:
Ricardo Palma has cultivated many literary genres. Journalism, epistolary, and literary translation are the least known of them. In general, this paper is about the letters sent by Ricardo Palma to Peruvian. Hispanic-American and Spanish writers, and, likewise, with the letters sent by Peruvian, Hispanic American and Spanish writers to Ricardo Palma.
\end{abstract}

Keywords: Ricardo Palma, letters, tradition, chronicles 
Pedro Díaz Ortiz (Perú): Escritor, traductor, editor. Doctor en Letras por la Universidad Nacional Mayor de San Marcos. Past-Decano de la Facultad de Humanidades y Lenguas Modernas de la Universidad Ricardo Palm, Ex Director de la Revista de la Facultad de Humanidades y Lenguas Modernas (URP). Director de la Serie "Letras Francesas". Ha publicado, entre otras obras, La estética teatral de Valle-Inclán; Un no rompido sueño; Edición crítica de la Primeria Serie de Tradiciones Peruanas, de Ricardo Palma; Albert Camus. Teatro y sociedad, y Gaudeamus. Ha realizado diversas traducciones de poesía francesa, entre otras de Blaise Cendrars, Raymond Queneau, Georgette Vallejo y André Coyné. 
En una carta dirigida a Francisco de Sosa, de fecha 28 de noviembre de 1889 , dando respuesta a un requerimiento del escritor mexicano, Ricardo Palma consigna algunos datos sobre su biografía y obra, de la que dice:

He sido periodista en diversas épocas de mi vida. No sé si lo hice bien o mal. En literatura he sido una especie de cajón de sastre. Cultivé todos los géneros, hasta que acerté con un filón, riquísimo para mí -el de las tradiciones-. El género cayó en gracia y me ha dado cierta popularidad (1949, p. 225).

En efecto, Ricardo Palma cultivó los más diversos géneros literarios, desde el periodístico hasta el epistolar y la traducción literaria, pero, como él mismo señaló, es en el género de la tradición en el cual obtuvo una pronta fama y fortuna, tal como fue reconocido por los diversos escritores hispanoamericanos de la época que emularon a Palma en el género creado por nuestro tradicionista que, luego, se convirtió en un género continental, como bien señala Estuardo Núñez en sus obras Tradiciones hispanoamericanas, reeditado luego con el título Ricardo Palma, Escritor Continental/Tras las huellas de Palma en los Tradicionistas Hispanoamericanos y los Tradicionistas Peruanos.

En el género epistolar -motivo de nuestra exposición-, de raigambre clásica y de gran importancia en las letras hispanoamericanas del siglo XIX, Ricardo Palma fue uno de sus representantes más preclaros, tal como advierte Raúl Porras Barrenechea en el prólogo al Epistolario de Ricardo Palma (Tomo I): "Palma fue, como hombre de su siglo, un incansable interlocutor epistolar. 'Jamás -dice con orgullo- he dejado sin respuesta inmediata carta alguna" (p. XIII). En efecto, la correspondencia de Palma es vasta. Por ello, como se dijo de José Martí, también puede afirmarse que Palma fue "un epistológrafo fecundísimo y proteico”. 
Sin embargo, de todos los géneros literarios cultivados por Palma, los menos conocidos y estudiados son, sin duda, el periodístico, el epistolar y la traducción literaria. Al respecto, entre los trabajos más importantes que se han escrito sobre los géneros mencionados tenemos el ensayo Palma periodista (1983) de Raúl Porras Barrenechea, y el excelente atisbo de algunos prólogos como el del mismo Raúl Porras al Epistolario de Ricardo Palma (Tomo I); el de Alberto Tauro del Pino a Semblanzas (1961); el de Rubén Vargas Ugarte a Cartas Inéditas (1964) de Ricardo Palma que, en una segunda edición, apareció con el título de Cartas a Piérola (1964); el de Luis Alberto Sánchez a Ricardo Palma-Diecisiete cartas inéditas con otras editas cambiadas con Doña Lola Rodríguez de Tió (1894-1907) (1968), y más recientemente Cartas indiscretas de Ricardo Palma / Comentadas por César Miró (1969), a los que hay que agregar los tres tomos del Epistolario General (2005), que reúnen las cartas de la correspondencia de Ricardo Palma entre los años 1846 y 1919, compiladas por Miguel Ángel Rodríguez Rea.

Los estudios sobre historia de la traducción literaria en el Perú, salvo algunos trabajos de Estuardo Núñez, son también muy escasos. Esta carencia ha empezado a ser resuelta con la tesis sobre la traducción literaria en el siglo XIX, en la que su autora Pilar Zuazo; trata sobre Palma traductor y las traducciones que se han hecho de sus tradiciones.

El Epistolario de Ricardo Palma fue publicado en dos tomos por la editorial Cultura Antártica en 1949. El Tomo I lleva un prólogo de Raúl Porras Barrenechea y contiene 93 cartas de Ricardo Palma dirigidas a escritores del Perú, Hispanoamérica y España; el Tomo II reúne 152 cartas de escritores peruanos, hispanoamericanos y españoles dirigidas a Ricardo Palma.

Las cartas que conforman los dos tomos del Epistolario de Ricardo Palma constituyen documentos de inapreciable valor 
no solo desde el punto de vista histórico y político sino también literario. Augusta y Renée Palma -hijas de Don Ricardo- dicen que esta colección de cartas es una especie de autobiografía fragmentada, pero además -como señala Porras-:

En las cartas de Palma hay apreciaciones y reflexiones constantes sobre la realidad política del Perú y sobre sus convicciones más íntimas en el orden social y nacional. Es interesante destacar ese ideario, sencilla y sinceramente expresado, porqué él contiene una decisiva enseñanza para el Perú, la del insigne escritor, que en el concepto carlyniano es guía, anunciador y héroe de su nacionalidad, porque dice y anticipa las verdades históricas o proféticas (p. XXIX).

Desde el punto de vista literario, el Epistolario de Palma es asimismo importante porque las cartas consignadas en sus dos tomos contienen testimonios de gran interés para la historia y exégesis del género de las tradiciones tales como la referencia a la publicación de las primeras series de las Tradiciones peruanas en sendos volúmenes; el reconocimiento de Palma como creador del género de las tradiciones, su propagación en los distintos países hispanoamericanos y los requisitos que debe reunir el género literario de la tradición para ser tal.

Respecto a la publicación de la Primera Serie de las Tradiciones, en una carta dirigida al escritor argentino Juan María Gutiérrez, el 26 de marzo de 1872, Palma le anuncia la publicación de la Primera Serie de sus Tradiciones: "Tengo listo un libro cuya impresión empezaré en junio. Lo componen Veinte tradiciones o leyendas peruanas. Si algún mérito tienen, es el de presentar en humilde prosa, acontecimientos de nuestra historia colonial" (1949, Tomo I, p. 13).

Entre 1872 y 1877, Palma mantiene una constante correspondencia con Juan María Gutiérrez, a quien le va 
informando de la publicación de la segunda, tercera y cuarta Serie de las Tradiciones Peruanas y, como otro dato, también importante para la exégesis del género de las tradiciones, en una carta de fecha 7 de julio de 1877, Palma dice: "En Alemania y traducidas a esa lengua, está publicando el Sr. D. Federico Leyhold los tres primeros tomos. Este caballero, me ha escrito una amabilísima carta sobre el particular" (1949, Tomo I, p. 31). Esta carta no figura en el Epistolario (Tomo II), tampoco en el Epistolario General (Tomo I).

En cuanto a la publicación del género de las traducciones en otros países hispanoamericanos, en una carta de 1875, Palma le dice a Juan María Gutiérrez que en Santiago de Chile se está imprimiendo un volumen de Tradiciones chilenas, escritas por Enrique del Solar, y asimismo que Miguel Luis Amunátegui también va a coleccionar las que ha publicado en los diarios, a lo cual añade: "Como usted ve ha entrado fiebre de tradicionar lo que francamente es halagador para mí que he sido el iniciador de este género de escritos". En la misma carta, Palma continúa diciendo:

un joven uruguayo, don Francisco Escardó, me escribe que va a publicar en Montevideo un libro de Tradiciones del Plata. Me ha enviado dos como muestra y tengo para mí que son mejores que las de Amunátegui. A pesar de su gran talento Amunátegui, en mi concepto ha escrito novelas y no tradiciones.

Creo que la tradición ante todo estriba en la forma. Deben narrarse como se narran los cuentos. La pluma debe correr ligera y ser sobria en detalles. Las apreciaciones deben ser rápidas. La filosofía del cuento o conseja ha de desprenderse por sí sola, sin que el autor lo diga. ¿Es usted de mi opinión? Por lo menos, así he concebido lo que debe ser la tradición (Tomo I, p. 20). 
Respecto a la filiación de las tradiciones, el colombiano Rafael Pombo, en carta dirigida a Ricardo Palma, el 18 de abril de 1891, le dice: "Usted con sus inimitables leyendas, ha creado ese género de literatura, ha inducido a muchos a novelizar nuestra historia, sin su estudio, sin su sal y primoroso desenfado del lenguaje" (Tomo II, p. 210).

Como vemos, en las citadas cartas, Palma advierte que es el iniciador (o creador) de las tradiciones como género literario ("un género de escritos", dice) y su influencia en la difusión del mismo en los distintos países hispanoamericanos.

La otra suma importante de las cartas de Palma son las que escribe a raíz del conflicto con Chile. Al respecto, el año 1964 se publicó el libro Ricardo Palma. Cartas inéditas. Su compilador y prologuista, el historiador Rubén Vargas Ugarte, dice, en primer lugar, que estas cartas constituyen lo más valioso del epistolario de Palma. En cuanto a su contenido, señala que las cartas dirigidas a Piérola

pueden dividirse en dos grupos: el más crecido y notable se refiere a los sucesos que tuvieron lugar en el Perú durante la ocupación chilena, del 25 de setiembre de 1880 hasta noviembre de 1881. Palma, que apreciaba mucho a D. Nicolás y era ferviente partidario suyo, se convierte en su corresponsal y va, casi día por día, dándole cuenta de todos los sucesos que ocurrían en Lima y aun en otras regiones del Perú. Por esta razón tienen un valor inapreciable y, aun bajo el punto de vista histórico, nos revelan muchas cosas que no hallamos en los libros de la materia (p. 64).

En 1979, Cartas Inéditas se reeditó con el título de Cartas a Piérola. Aparte del mismo prólogo de Rubén Vargas Ugarte, el libro contiene una nota de su editor, Carlos Milla Batres, quien refiriéndose a las cartas de Palma dice que ellas reiniciaron 
en nuestro tiempo la reparación histórica de la guerra con Chile de 1879, tan soslayada no solo oficialmente sino también por la historiografía de la prudencia, como si los hechos que ensombrecieron a la nación y enlutaron a la familia peruana pudieran, después de un siglo, seguirse cubriendo con tibiezas (p. 7).

Carlos Milla sigue diciendo que algunas páginas de Cartas a Piérola

podrán parecer muy duras, pero creemos sinceramente en que no hay otra forma de poder ser libres para emprender una nueva historia o para formar una conciencia ciudadana heroica, a fin de que esa historia dolorosa del 79 no vuelva a repetirse (ibíd.).

En este sentido, Cartas a Piérola tiene una íntima relación con las crónicas que Ricardo Palma, con el pseudónimo de Hiram, enviaba al periódico Canal que se publicaba en Panamá durante el período de la ocupación chilena en Lima. Dicho periódico, fundado en abril de 1881 por Federico Larrañaga -Cónsul General del Perú en la ciudad de Panamá-, defendió la causa del Perú en la Guerra con Chile. Las crónicas de Palma fueron publicadas el año 1984 con el título de Crónicas de la Guerra con Chile.

Respecto al rol e importancia del periódico Canal, Ricardo Palma le escribe lo siguiente a Piérola en junio de 1881:

Y á propósito del "Canal”. Me escribe Larrañaga que hace grandes sacrificios para sostener esa publicación, la cual corre riesgo de morir si no recibe pronto auxilio pecuniario de U. Gran lástima sería, pues es hoy el único órgano con que contamos para desenmascarar a los enemigos de casa y á los chilenos. El "Canal” ejerce en las repúblicas colombianas y en Estados Unidos utilísima propaganda, y en 
Lima se arrebatan y corren de mano en mano los números. En mi concepto sostener ese periódico nos es tanto o más necesario que aumentar el ejército con un batallón. Como dijo -no recuerdo quien- la prensa es el cañón rayado de la intelijencia; y más barata, en todo caso, que una batería de seis cañones Krup, y de efectos más seguros.

$[\ldots]$

Larrañaga me dice que ha escrito á U. y á D. Carlos y al Dr. Arenas, infinitas cartas manifestando sus apuros para sostener la imprenta, sin recibir hasta ahora una respuesta satisfactoria. Ygnorando él mis percances de Miraflores ${ }^{1}$ y mi mala situación rentista se dirige ahora á mí; fatalmente no puedo hacer más que colaborar como periodista guerrillero y abusar de la benevolencia con que U. acoje mis cartas para empeñarme en pedirle que atienda lo que yo juzgo lejítima exijencia de Larrañaga. Periodista ha sido U., conoce a fondo el oficio y no necesita, por lo tanto, que le ponga puntos sobre las íes para estimar la conveniencia ó inconveniencia de tener en Panamá un órgano exclusivamente peruano, ya que en Lima es ello imposible mientras nos dominen chilenos y achilenados (1964, pp. 40-41, las negritas son nuestras).

La Lima ocupada por la soldadesca invasora es, pues, el escenario desde el cual Ricardo Palma escribe sus crónicas. La tarea, evidentemente, no era fácil. Al respecto, Jorge Basadre señala que Patricio Lynch, jefe de las fuerzas chilenas, dictó un decreto según el cual "quedó prohibida la publicación de libros, periódicos, folletos y hojas sueltas sin permiso del Cuartel General”. Y asimismo “ordenó perseguir tenazmente e imponer severos castigos a los que, en contravención de lo decretado,

I Palma se refiere al incendio de su casa y biblioteca en Miraflores por las hordas chilenas. 
dieran a la luz pública proclamas, libelos, pasquines u otra clase de impresos políticos" (Basadre, 1969, p. 326.).

Esta situación explica el porqué de los pseudónimos utilizados por Palma en la firma de sus crónicas enviadas al diario El Canal en Panamá y en muchas de las cartas dirigidas a Piérola. Actuar contra las disposiciones impuestas por las fuerzas ocupantes suponía un grave riesgo que Palma conocía, pero así y todo fue asumido por él con valor y patriotismo.

Al respecto, en su carta del 12 de agosto de 1881, Ricardo Palma le dice a Piérola que por informes de un delator

se ha sabido que soy yo el corresponsal en Lima del "Canal", lo que me acarreó una retahíla de injurias editoriales en el "Orden", del día 4 y amagos de persecución chilena que, gracias á la influencia de un amigo europeo, ha cesado ya (1964, p. 51, las negritas son nuestras).

Por su parte, la crónica del 23 de noviembre de 1881 consigna, entre otras noticias, la siguiente:

El renombrado literato don Ricardo Palma fue aprehendido por la policía chilena el 16, y hoy se encuentra a bordo, en el Callao, en el pontón "Valdivia" en vísperas de marchar a Chile. Se ignora la causa de la prisión de Palma; pero se le atribuyen ciertos pecadillos de pluma, de que lo creo inocente (Palma, 1984, p. 107).

En efecto, Palma, sospechoso de ser el Hiram-corresponsal del Canal, estuvo preso una noche, pero luego fue liberado. Su prestigio de gran escritor contribuyó, sin duda, a su pronta libertad. Su rol de corresponsal se desarrolló, pues, dentro de las peripecias y riesgos de un periodista guerrillero, como el mismo solía llamarse. 
Como vemos, tanto en las cartas como en las crónicas de Palma, aparte del concepto carlyniano señalado por Porras, está también presente el concepto sartreano de la literatura comprometida que borra toda filiación de Palma con una literatura pasadista o colonialista que, en algún momento, sostuvo una crítica equivocada.

\section{Bibliografía}

Basadre, J. (1969). Historia de la República del Perú. Lima: Ed. Universitaria.

Núñez, E. (1979). Tradiciones hispanoamericanas. Caracas: Biblioteca Ayacucho.

Núñez, E. (1998). Ricardo Palma, Escritor Continental/Tras las huellas de Palma en los Tradicionistas Hispanoamericanos. Lima: Ed. Banco Central de Reserva del Perú.

Núñez, E. (2001). Los tradicionistas peruanos. Perú: Editorial Laberintos.

Palma, R. (1949). Epistolario. Tomos I y II. Lima: Editorial Antártica.

Palma, R. (1961). Semblanzas. Lima: Editorial Mejía Baca.

Palma, R. (1979). Cartas a Piérola. Lima: Editorial Carlos Milla Batres.

Palma, R. (1964). Cartas Inéditas. Lima: Editorial Carlos Milla Batres.

Palma, R. (1968). Diecisiete cartas inéditas con otras éditas cambiadas con Doña Lola Rodríguez de Tió (1894-1907). Lima: Editorial UNMSM.

Palma, R. (1969). Cartas indiscretas de Ricardo Palma / Comentadas por César Miró. Lima: Francisco Moncloa editores. 
Palma, R. (1984). Crónicas de la guerra con Chile. Lima: Ed. Mosca Azul.

Palma, R. (2005). Epistolario General. Edición, prólogo, notas e índices de Miguel Ángel Rodríguez Rea. Lima: Editorial URP.

Palma, R. (2008). Tradiciones Peruanas. Primera Serie. Edición Crítica de Pedro Díaz Ortiz. Lima: Ed. Pedro Díaz Ortiz.

Porras Barrenechea, R. (1983). Palma Periodista. En Revista de la Universidad Ricardo Palma, N 6, pp. 5-30.

Zuazo Mantilla, P. (2018). Función de los traductores literarios durante la República peruana en el siglo XIX (1850-1900): El caso de cuatro traductores literatos. Tesis de Maestría. Lima: Universidad Ricardo Palma.

Recibido el 20 de octubre de 2019 Aceptado el 28 de octubre de 2019 